\title{
The effect of circadian rhythms on shipping accidents - CORRIGENDUM
}

Juan Vinagre-Ríos, José-Manuel Pérez-Canosa, and Santiago Iglesias-Baniela

doi: 10.1017/S0373463321000333, Published by Cambridge University Press, 13 April 2021.

Keywords: safety, human error, bridge, corrigendum

The Authors apologise for a grammatical mistake in the last sentence of the Abstract. Therefore, where it reads:

"A sample of vessel collisions was analysed and it was find out that this kind of accident tends to be more frequent and more serious during the darkness period of the solar day".

It should read as follows:

"A sample of vessel collisions was analysed and it was found out that this kind of accident tends to be more frequent and more serious during the darkness period of the solar day"

\section{Reference}

Vinagre-Ríos, J., Pérez-Canosa, J.-M. and Iglesias-Baniela, S. (2021). The effect of circadian rhythms on shipping accidents. Journal of Navigation. Published by Cambridge University Press, 13 April 2021. doi: 10.1017/S0373463321000333. 